\title{
An Empirical Study on the Impact of Online Travel Consumers' Brand Loyalty:The Mediating Effect of Flow Experience
}

\author{
Shuyan Xie ${ }^{1}$,Yazhong Yuan ${ }^{2}$ \\ ${ }^{1}$ School of Geography and Tourism, Guangdong University of Finance and Economics, Guangzhou, China \\ ${ }^{2}$ School of Geography and Tourism, Guangdong University of Finance and Economics, Guangzhou, China
}

\begin{abstract}
In recent years, virtual reality (VR) technology has developed vigorously, and how to make good use of virtual reality technology to create virtual tourism has become an important topic for tourism ecommerce. Previous studies have shown that creating a good online experience for consumers is an effective way for e-commerce to establish consumer brand loyalty, but there are few literatures focusing on the special group of online travel consumers. Based on the flow theory, the article uses Chinese online travel consumers as a sample to conduct empirical research, focusing on exploring the relationship between consumer perception of VR technology and brand loyalty, and testing the mediating effect of flow experience. The results show that: (1) the perceived usefulness and ease of use of VR technology have a significant positive impact on consumers' online experience; (2)the flow experience of travel consumers has a significant positive impact on their brand loyalty; (3) the perceived usefulness and ease of use of VR technology have a significant positive impact on consumers' brand loyalty;(4)the flow experience has a mediating effect between the perception of VR technology and brand loyalty of travel consumers.
\end{abstract}

\section{INTRODUCTION}

With the development of VR technology, virtual tourism has become a new form for modern tourists to experience travel online. The application of virtual reality technology on online travel websites can enable online travel consumers to enjoy it free of time and space. Therefore, travel consumers' perception of virtual reality technology also constitutes one of the core competitiveness of travel e-commerce. How to win the online travel consumers' brand loyalty by VR technology has become an important topic of travel e-commerce. Previous studies have shown that a good online experience of consumers can effectively help travel e-commerce to influence consumers' brand loyalty. However, few studies have focused on the special group of online travel consumers, and have failed to elaborate on the mechanism of online travel consumers' flow experience between the perception of the new technology of VR and brand loyalty. Based on the flow experience and SOR paradigm, this article uses the two traditional TAM variables, perceived ease of use and perceived usefulness, to measure consumer perception of VR technology, and builds the immersion of VR technology by adding new variables (flow experience) to build the influence mechanism of experience on online travel consumer loyalty.

\section{REVTEW AND HYPOTHESIS}

\subsection{Flow experience}

Flow experience is the core concept of flow theory. Flow theory was first proposed by the American psychologist Csikszentmihalyi. This theory describes the overall feeling that an individual feels when he is fully engaged in an activity, so as to achieve a state of immersion [3] [4]. In the past, flow experience was mostly used in consumer behavior research, psychology, human-computer interaction and information systems, education management and other fields. In recent years, more and more scholars have confirmed the important role of flow experience in the online environment through their research. Studies have found that flow experience will have a positive impact on online consumer behavior, including the willingness to visit the website again [5], good presentation effects [7], user stickiness [6]. Although many scholars have conducted empirical research on the role of flow experience, few scholars have paid attention to the mechanism of flow experience between perceived ease of use, perceived usefulness and brand loyalty in the research field of online travel companies.

\subsection{Perceived ease of use, perceived usefulness and flow experience}

Virtual reality technology, also known as spiritual environment technology, is mainly used to generate a virtual environment through multi-source information 
fusion, which can make users immerse in the simulated environment and produce flow experience [21]. It was Perry Hobson and Williams [22] who first proposed the integration of VR technology with the tourism industry, who proposed to combine the two to give birth to a new format, namely virtual tourism. It dynamically presents tourism landscapes in reality or non-existent in front of people through virtual reality technology, so that tourists can get an immersive travel experience without leaving home. As for the measurement of new technologies such as VR, the academic community generally uses the wellknown Technology Acceptance Model (TAM), which was proposed by Davis in 1989 to explain and predict users' use and acceptance of information systems. It is proposed that Perceived Ease of Use (PEU) and Perceived Usefulness (PU) are the main factors that determine the acceptance of information technology systems [1].

In the network environment, online experience and technological environment stimulation will serve as a response mechanism of consumer experience, and the flow experience environment created by it will bring consumers a better consumer experience and a good presentation effect [7]. Through investigations, TAO pointed out that the perceived ease of use of emerging technologies has a significant impact on the immersion experience [15]. The research of Liao Chenglin [14], Liu Yan et al. [9] also confirmed this view. Their research shows that the perceived ease of use and perceived usefulness of consumers' online experience is beneficial to consumers' flow experience [9]. Therefore, this article proposes the following hypotheses:

H1: The perceived ease of use of VR technology positively affects the flow experience.

H2: The perceived usefulness of VR technology positively affects the flow experience.

\subsection{Flow experience and brand loyalty}

Brand loyalty refers to a strong sense of commitment to repurchase a preferred product or service. This sense of commitment leads to repeated purchases of a specific brand, even if the purchase situation and marketing methods at the time may lead to purchase behavior [10]. This article mainly discusses consumers' brand loyalty to travel e-commerce. In this regard, different scholars have proposed its influence path from different perspectives. Skadberg and Kimmel pointed out through their empirical research that when Internet users reach a state of immersion, they will improve learning and lead to positive changes in attitudes and participation behaviors [11]. The research of Zhou [12] and $\mathrm{Hu}$ Wenyu [13] also supports this view, and they found that the flow experience is beneficial to consumers' brand loyalty [12]. Lin Yan et al. believe that online flow experience not only positively affects customer brand loyalty, but also demonstrates that customer fit plays an intermediary role between online flow experience and brand loyalty [20]. Therefore, the following hypothesis is made:

H3: Flow experience positively affects brand loyalty.

\subsection{Perceived ease of use 、 perceived usefulness and brand loyalty}

The perceived ease of use and perceived usefulness of emerging technologies can better explain consumer' trust and purchase intentions in the context of Internet shopping [2]. Through experimental methods, Zhong Shuai et al. pointed out that the usefulness perception and reliability perception of online reviews can both improve consumer loyalty to website brands. Some scholars also demonstrate the relationship between the two by constructing a relationship model. Wang Lilei builds a model of the relationship between consumers' perception of online reviews and website brand loyalty, and believes that online reviews are useful and positively affect brand loyalty [16]. In addition, the ease of use and usefulness of emerging technologies will positively affect customer brand loyalty through customer value [17]. Therefore, the following hypotheses are made:

H4: The perceived ease of use of VR technology positively affects brand loyalty.

H5: The perceived usefulness of VR technology positively affects brand loyalty.

\subsection{The Mediating Effect of Flow Experience}

Existing research has found that the good perception of emerging technologies brings customers a deep consumer experience, which further affects consumer psychology and attitudes, such as user stickiness and trust. For example, through research, Zhu Jingwen et al. pointed out that perceived ease of use, perceived usefulness and involvement significantly positively affect flow experience, and these factors further significantly affect user stickiness through flow experience [18]. Liu Yan et al. took online travel consumers as the object, and the study found that the perceived ease of use of travel consumers has a significant positive impact on perceived usefulness, which in turn has a positive impact on consumers' brand trust [9]. Research by Ling et al. also pointed out that flow experience will have a positive and significant impact on online consumers' brand recognition and repurchase intentions [19]. Therefore, this article proposes the following hypotheses:

H6: Flow experience has a mediating effect between the perceived ease of use of VR technology and brand loyalty.

H7: Flow experience plays a mediating effect between the perceived usefulness of VR technology and brand loyalty.

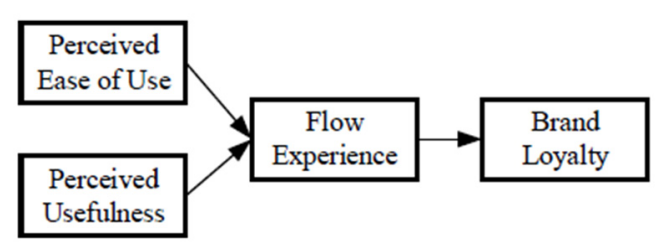

Fig 1. Theoretical model

Based on the above research hypotheses, this research has drawn a theoretical model diagram of the causal relationship between perceived ease of use, perceived 
usefulness, flow experience, and brand loyalty, as shown in Figure 1. The independent variables are perceived usefulness and perceived usefulness, the mediating variable is flow experience, and the dependent variable is brand loyalty.

\section{METHODS}

\subsection{Sample and procedures}

This article first invites 15 online travel consumers to conduct a pre-survey, and then revises the questionnaire based on the feedback from the interviewees to ensure that the interviewees can accurately understand and answer the questionnaire during the formal survey. This questionnaire adopts the online questionnaire survey method. The questionnaire is posted on the questionnaire star, and the questionnaire is posted through QQ or WeChat group, and at the same time, relevant users are invited to participate in the survey through the on-site paper QR code.

The questionnaire collection work lasted for 4 weeks. A total of 298 questionnaires were collected, 32 invalid questionnaires were deleted, and 266 valid questionnaires were obtained. The effective rate was $89.26 \%$. The sample size met the requirements of this research. Among all the respondents, males accounted for $73.3 \%$ and females accounted for $26.7 \%$.

\subsection{Measures}

A total of 4 variables are included in the research model in this paper. In order to ensure the content validity of the constructs and items, each construct and item is referenced from mature scales at home and abroad. All variables are measured using a 5-point Likert scale, ranging from 1-5 which means strongly disagree to strongly agree.

Perceived ease of use (Cronbach $\alpha=0.82$ ). We refer to the research of Davis F.D. [1], with a total of 3 items, including that learning VR technology related knowledge is easy, mastering VR technology is very simple.

Perceived usefulness (Cronbach $\alpha=0.70$ ). We refer to the research of Davis F.D. [1], with a total of 3 items, including that VR technology can save a lot of time, VR technology can improve browsing efficiency.

Flow experience (Cronbach $\alpha=0.73$ ). We refer to the research of Yan et al. [23] with a total of 4 items, including that when I focus on VR technology experience, I feel that time flies too fast, and when I use VR technology, I feel curious and enjoy.

Brand loyalty (Cronbach $\alpha=0.86$ ). We refer to the research of Oliver [10], a total of 6 items, including that I often use the travel website or APP, I think I am a loyal supporter of the travel website or APP.

\section{Result}

\subsection{Confirmatory factor analysis}

In this study, confirmatory factor analysis (CFA) was used to test the discriminative validity between variables. In the comparison of single-factor model, two-factor model, three-factor model and four-factor model (Table 1), it can be seen that the four-factor model shows good fit in the comparison model $\left(\chi^{2} / \mathrm{df}=2.421\right.$; RMSEA $=0.073$; TLI $=0.909 ; \quad C F I=0.926)$. This shows that the four variables are indeed different constructs and have ideal discriminative validity. It also empirically supported the distinctiveness of the four variables for subsequent analyses.

Table1. RESULTS OF CONFIRMATORY FACTOR ANALYSIS

\begin{tabular}{lcccccc}
\hline Model & $\chi^{2}$ & df & $\chi^{2} / \mathbf{d f}$ & RMSEA & TLI & CFI \\
\hline $\begin{array}{l}\text { Single- } \\
\text { factor } \\
\text { model }\end{array}$ & 418.861 & 104 & 4.028 & 0.107 & 0.806 & 0.832 \\
\hline $\begin{array}{l}\text { Two- } \\
\text { factors } \\
\text { model }\end{array}$ & 336.961 & 103 & 3.271 & 0.093 & 0.855 & 0.875 \\
\hline $\begin{array}{l}\text { Three- } \\
\text { factors } \\
\text { model }\end{array}$ & 283.311 & 101 & 2.805 & 0.083 & 0.885 & 0.903 \\
\hline $\begin{array}{l}\text { Four- } \\
\text { factors } \\
\text { model }\end{array}$ & 237.252 & 98 & 2.421 & 0.073 & 0.909 & 0.926 \\
\hline
\end{tabular}

Note: Single factor: perceived ease of use + perceived usefulness + flow experience + brand loyalty; Two factors: perceived ease of use + perceived usefulness + flow experience , brand loyalty; Three factors: perceived ease of use + perceived usefulness, flow experience, brand loyalty; Four factors: perceived ease of use, perceived usefulness, flow experience, brand loyalty.

\subsection{Correlation Analysis}

Correlation analysis aims to study the correlation between variables (Table 2). Research shows that perceived ease of use and perceived usefulness are significantly positively correlated with flow experience; flow experience is significantly positively correlated with brand loyalty. In addition, perceived ease of use and perceived usefulness are significantly positively correlated with brand loyalty. These results provide the necessary premise for the analysis of the relationship between the research variables. 
Table2. Correlation Analysis

\begin{tabular}{llllllllll}
\hline & M & SD & $\mathbf{1}$ & $\mathbf{2}$ & $\mathbf{3}$ & $\mathbf{4}$ & $\mathbf{5}$ & $\mathbf{6}$ & $\mathbf{7}$ \\
\hline 1 Gender & 1.733 & 0.443 & 1 & & & & & & \\
2 Age & 1.015 & 0.150 & -0.110 & 1 & & & & & \\
3 Education & 2.049 & 0.315 & -0.068 & $0.304^{* *}$ & 1 & & & & \\
4 Perceived ease of use & 3.799 & 0.835 & $0.147^{*}$ & -0.056 & -0.030 & 1 & & & \\
5 Perceived usefulness & 3.939 & 0.708 & 0.008 & -0.003 & 0.002 & $0.597^{* *}$ & 1 & & \\
6 Flow experience & 3.860 & 0.705 & 0.085 & 0.002 & 0.069 & $0.631^{* *}$ & $0.627^{* *}$ & 1 \\
7 Brand loyalty & 3.771 & 0.751 & -0.009 & -0.120 & 0.063 & $0.596^{* *}$ & $0.566^{* *}$ & $0.654^{* *}$ & 1 \\
*** $<0.01 ;^{*} \mathrm{p}<0.05$. & & & & & & & & &
\end{tabular}

\subsection{Hypothesis testing}

Table 3 shows the regression results of technological perception and other variables on brand loyalty. As shown in model 2 in table 3, after controlling the influence of variables (gender, age, education), perceived ease of use $(\beta=0.412, p<0.001)$ and perceived usefulness $(\beta=0.320$, $\mathrm{p}<0.001$ ) have a significant positive effect on brand loyalty Therefore, hypothesis 4 and hypothesis 5 are supported. At the same time, model 3 shows that flow experience has a significant positive effect on brand loyalty $(\beta=0.388$, $\mathrm{p}<0.001)$. Therefore, hypothesis 3 is supported. In addition, it can be seen from model 5 that after controlling the influence of variables (gender, age, education), perceived ease of use $(\beta=0.397, p<0.001)$ and perceived usefulness $(\beta=0.389, p<0.001)$ have a significant positive impact on the flow experience. Therefore, hypothesis 1 and hypothesis 2 are supported.

In this study, the mediating effect test model proposed by Baron et al. [26] was mainly used to test the mediation effect of flow experience. First, model 2 in table III shows that perceived ease of use has a significant impact on brand loyalty; and model 5 shows that perceived ease of use has a significant impact on flow experience. And it can be seen from model 3 that after adding a mediation variable (flow experience), flow experience has a significant explanatory power for brand loyalty ( $\triangle R^{2}$ is positive and significant). Consequently, it can be seen from models 2 and 3 that after adding the mediation variable (flow experience), the predictive power of perceived ease of use is reduced from 0.412 (significant) to 0.257 (significant), and the explanatory power $\mathrm{R}^{2}$ is increased from 0.440 to 0.515 , which supports hypothesis 6 . Therefore, flow experience has a mediating effect between the perceived ease of use of VR technology and brand loyalty, and the result belongs to partial mediation.

Similarly, from model 2 in table 3, it can be seen that perceived usefulness has a significant impact on brand loyalty; and from model 5 , it can be seen that perceived usefulness has a significant impact on flow experience. And it can be seen from model 3 that after adding a mediation variable (flow experience), flow experience has a significant explanatory power for brand loyalty $\left(\triangle R^{2}\right.$ is positive and significant). Consequently, it can be seen from models 2 and 3 that after adding a mediation variable (flow experience), the predictive power of perceived usefulness is reduced from 0.320 (significant) to 0.169 (significant), and the explanatory power $\mathrm{R}^{2}$ is increased from 0.440 to 0.515 , which supports hypothesis 7 . Therefore, flow experience has a mediating effect between the VR technology perceives usefulness and brand loyalty, and the result belongs to partial mediation.

Table3. RESULTS OF REGRESSION ANALYSIS FOR MAIN EFFECT AND MODERATE EFFECT

\begin{tabular}{|c|c|c|c|c|c|}
\hline & \multicolumn{3}{|c|}{ Dependent Variables: Brand loyalty } & \multicolumn{2}{|c|}{ Dependent Variables: Flow experience } \\
\hline & Model 1 & Model 2 & Model 3 & Model 4 & Model 5 \\
\hline \multicolumn{6}{|l|}{ Control Variables } \\
\hline Gender & -0.018 & -0.080 & $-0.091 *$ & 0.089 & 0.030 \\
\hline Age & $-0.155^{*}$ & -0.139 & $-0.140^{*}$ & -0.012 & 0.004 \\
\hline Education & 0.109 & 0.112 & 0.080 & 0.079 & 0.081 \\
\hline \multicolumn{6}{|l|}{ Independent Variables } \\
\hline Perceived ease of use & & $0.412 * * *$ & $0.257 * * *$ & & $0.397 * * *$ \\
\hline Perceived usefulness & & $0.320 * * *$ & $0.169^{* *}$ & & $0.389 * * *$ \\
\hline \multicolumn{6}{|l|}{ Mediator } \\
\hline Flow experience & & & $0.388 * * *$ & & \\
\hline $\mathrm{R}^{2}$ & 0.026 & 0.451 & 0.526 & 0.013 & 0.503 \\
\hline Adjusted $\mathrm{R}^{2}$ & 0.015 & 0.440 & 0.515 & 0.002 & 0.493 \\
\hline$\triangle \mathrm{R}^{2}$ & 0.026 & 0.425 & 0.075 & 0.013 & 0.490 \\
\hline$\triangle \mathrm{F}$ & 2.312 & $100.656^{* * *}$ & $40.948 * * *$ & 1.153 & $128.067 * * *$ \\
\hline
\end{tabular}




\section{RESEARCH CONCLUSIONS AND DISCUSSION}

\subsection{Research conclusions}

Based on the flow theory and technology acceptance model, this paper establishes the mechanism of the online experience of travel consumers' perception of VR technology on website brand loyalty from the perspective of customer flow experience, and explains the mediating role played by flow experience. The research results show that the perceived ease of use and perceived usefulness of VR technology positively affect online travel consumers' flow experience and brand loyalty; and the flow experience generated by online travel consumers has a significant impact on consumers' brand loyalty. In addition, consumers' flow experience has a mediating effect between perception of VR technology and brand loyalty.

\subsection{Theoretical and management Implications}

Flow theory can help us understand the impact of VR technology perception on the brand loyalty of online travel consumers. The research results show that:

(1) Online travel consumers' perceived ease of use and perceived usefulness of VR technology have a significant positive impact on consumers' flow experience, which is consistent with the research conclusions of Liu Yan [9] and Tao [15]. This study found that the overall flow experience of travel consumers when browsing travel products online will be affected by the perceived usefulness and ease of use of the VR technology used by the website. The result of that research indicates that travel e-commerce manager should consider the usefulness and ease of use and other factors, such as clearly classified navigation, convenient keyword search tools, and quick switching between different pages, which can significantly improve the flow experience of online travel consumers, thereby cultivating online travel brand loyalty of the product.

(2) Flow experience has a mediating effect between the VR technology perception and brand loyalty. This conclusion provides a more comprehensive description of the psychological state of online travel consumers under different e-commerce stimuli. It explains the mechanism of the customer's VR technology perception experience on customer online behavior. The results of this research show that the flow experience of online travel consumers can perceive good preconditions through the good VR technology created by online travel e-commerce, such as the usefulness and ease of use of online products. The enlightenment of the research conclusion is that travel ecommerce manager needs to pay attention to the perceived usefulness and perceived ease of use of its online VR technology, which can create conditions for consumers to produce a good flow experience, such as optimizing the performance of VR technology and simplifying its operations.

\subsection{Limitations and Future Suggestions}

This study only combed the pre-variables that affect travel consumers' brand loyalty to online e-commerce from the perspective of flow theory, and examined the mediating role of flow experience in consumers' perception of VR technology and brand loyalty. The research results can provide new research perspectives for follow-up researchers, but there are still some limitations. First, the sample size is too small. China's online travel users have reached a certain scale. Whether the conclusions drawn from more than 260 samples drawn from online and field surveys are applicable to all online travel consumers remains to be further tested by a large sample. Second, time-point investigation. This research uses a crosssectional survey at a certain point in time rather than a longitudinal time series survey. Consumers' psychological state and purchasing behavior will show different fluctuations as the internal and external environments change. Future research should increase the vertical time series, which could deeply analyze the relationship between customer's technical perception and brand loyalty. Third, this research talks about flow experience as a single-dimensional concept, but Rose et al. pointed out that the concept of flow experience is relatively broad and should be regarded as a multi-dimensional concept, such as inner enjoyment, concentration, which can consider from the knowledge and perception [27]. Future research directions can consider how different pre-variables affect different stages of flow experience.

\section{ACKNOWLEDGEMENT}

This study was supported by Guangdong Graduate Education Innovation Project (Grant number2019SFKC28). And thanks to all the interviewees that help to cooperated with this study.

\section{REFERENCES}

1. Davis F D. Perceived usefulness, perceived ease of use, and user acceptance of information technology [J]. MIS Quarterly,1989, 13(3):319-340.

2. Ventakesh V., Michael G., Morris G.B.. User Acceptance of Information Technology: Toward a Unified View [J].MIS Quarterly,2003,27(3):425-478.

3. Csikszentmihalyi M. Play and intrinsic rewards $[\mathrm{J}]$. Journal of Humanistic Psychology,1975,15(3):41-63.

4. Csikszentmihalyi M. Finding Flow: The Psychology of Engagement with Everyday Life [M]. New York: Basic Books, 1997:22.

5. Van Nooat G,VoorveldO Ham,Van Reijmersdal E A.Interactivity in brand web sites:cognitive, affective, and behavioral responses explained by consumers'online flow experience[J].Journal of Interactive Marketing, 2012， 26(4):223-234.

6. Dang Yiwei, Shi Guicheng, Zhang Hongmin. Immersive experience and advertising patience: how to improve the stickiness of content website viewers? [J]. Modern Finance (Journal of Tianjin University of Finance and Economics), 2020, 40 (04): 82-93.

7. Mollen A, Wilson H. Engagement, telepresence and interactivity in online consumer experience: 
Reconciling scholastic andmanagerial perspectives [J]. Jounal of Business Research,2010,63(9):919-925.

8. Zhong Shuai, Wang Lilei, Zhang Qiyu. The impact of online comment perception and involvement on website brand loyalty[J]. Enterprise Economics, 2015(04): 36-40.

9. Liu Yan, $\mathrm{Pu}$ Bo, Guan Zhenzhong. The influence of travel consumers' online experience on rebooking from the perspective of flow theory[J].Tourism Tribune, 2016, 31(11): 85-95.

10. Richard Oliver, Whence consumer loyalty?[J].Journal of Marketing,1999,63(Special Issue 1999):33-44.

11. Skadberg,Y.X, Kimmel,J.R. Visitors' flow experience while browsing a web site: Its measurement $[\mathrm{J}]$.contributing factors and consequences. Computers in Human Behavior,2004(20),403-422.

12. ZHOU T, LI H, LIU Y. The effect of flow experience on mobile SNS users' loyalty[J]. Industrial Management \& Data Systems, 2010, 110(6):930-946.

13. $\mathrm{Hu}$ Wenyu. Research on online purchase intention based on flow experience theory[D]. Beijing University of Posts and Telecommunications, 2012.

14. Liao Chenglin, Gong Xiaoyan, Li Yi. An Empirical Study on the Impact of New Customers' Website Perception and Trust on Their Online Purchasing Behavior [J]. Technoeconomics, 2012, 31(1): 16-21.

15. TAO ZHOU. The effect of flow experience on user adoption of mobile TV[J]. Behaviour \& Information Technology,2013,32(3):263-272.

16. Wang Lilei, Zhang Jianyu, Zhong Shuai. Research on the Impact of Consumers' Perception of Online Reviews on Website Brand Loyalty [J]. Consumer Economy, 2013, 29(06): 40-45.

17. Pan Guangfeng. Research on the Mechanism of the Influence of Website Features on Internet Brand Loyalty [D]. Shandong University, 2013.

18. Zhu Jingwen, Fang Aihua, Liu Kunfeng. Research on the Influence of Mobile Reading Flow Experience on User Stickiness[J]. Editor's Friends, 2017(04): 13-18.

19. Ling K C, Chai L T, Piew T H. The effects of shopping orientations' online trust and prior online purchase experience toward customers' online purchase intention [J]. International Business Research, 2010, 3(3): $63-76$.

20. Lin Yan, Yu Shasha. Online flow experience, customer engagement and brand loyalty-Based on the VR perspective of online shopping[J]. Economics and Management, 2019, 33(06): 44$49+71$.

21. Liu Peilin. Virtual reality and the networked presentation of tourist characteristic towns[J]. Tourism Tribune, 2018, 33(06): 3-5.

22. PERRY HOBSON J S, WILLIAMS A P Virtual reality : A new horizon for the tourism industry [J]. Journal of Vacation Marketing, 1995, 1 (2) : 125-135.
23. Yalan Yan, Robert M. Davison, and Chunyan Moa. Employee Creativity Formation: The Roles of Knowledge Seeking, Knowledge Contributing and Flow Experience in Web 2.0 Virtual Communities [J]. Computers in Human Behavior, 2013,29:1923-1932.

24. Preacher K J, Hayes A F. SPSS and SAS procedures for estimating indirect effects in simple mediation model[J]. Behavior Research Methods, Instruments, and Computers,2004,36:717-731.

25. Hayes A F. An introduction to mediation, moderation and conditional process analysis: A regression-based approach[M]. New York: Guilford Press, 2013.

26. Baron, R.M., Kenny, D.A.. The Moderator-Mediator Variable Distinction in Social Psychological Research: Conceptual, Stra- tegic, and Statistical Considerations. Journal of Personality and Social Psychology, 1986, 51(6): 1173-1182.

27. Rose S, Clark M, Samouel P, et al. Online customer experience in e- retailing: An empirical model of antecedents and outcomes[J]. Journal of Retailing, 2012, 88(2): 308-32. 